\title{
Autoimmune myelofibrosis associated with autoimmune hemolytic anemia successfully treated with ruxolitinib
}

Shuku Sato ( $D$ ocukuhs719@gmail.com )

Shonan Kamakura General Hospital https://orcid.org/0000-0003-1025-1201

Wataru Kamata

Shonan Kamakura General Hospital: Shonan Kamakura Sogo Byoin

Yotaro Tamai

Shonan Kamakura General Hospital: Shonan Kamakura Sogo Byoin

\section{Research Article}

Keywords: aiha, hemolytic, anemia, splenomegaly, bone

Posted Date: September 15th, 2021

DOl: https://doi.org/10.21203/rs.3.rs-363573/v1

License: (c) (i) This work is licensed under a Creative Commons Attribution 4.0 International License.

Read Full License 


\section{Abstract}

A 55-year-old man suffered from dyspnea, general malaise, and jaundice. His laboratory date showed pancytopenia and hemolytic anemia, and computed tomography showed splenomegaly. Bone marrow examination revealed myelofibrosis (MF)-1. The hemolytic anemia was diagnosed as IgM autoimmune hemolytic anemia (AlHA) with negative direct and indirect Coombs test but positive IgM-direct antiglobulin test. We started ruxolitinib $20 \mathrm{mg}$, which improved not only bone marrow fibrosis, symptoms related to myeloproliferative neoplasms and splenomegaly, but also AlHA. AlHA may be associated with Autoimmune MF (AIMF), and cytokines such as transforming growth factor (TGF)- $\beta$ are thought to be involved in such cases. This case suggests that ruxolitinib may improve the cytokine levels and may lead to the treatment of AlHA as well as AIMF.

\section{Introduction}

Autoimmune myelofibrosis (AIMF) is secondary MF associated with autoimmune diseases [1]. In many cases, single-agent prednisolone can induce blood cell recovery; however, few cases show complete improvement of fibrosis. We report the first case of rapid improvement of myelofibrosis and improvement of the autoimmune disease itself in a patient with AIMF treated with ruxolitinib monotherapy.

\section{Case Presentation}

A 55-year-old man presented with dyspnea, general malaise, and jaundice since 3 months that gradually worsened. Abdominal CT showed splenomegaly (Fig. 1a); laboratory tests showed pancytopenia (white blood count $2.2 \times 10^{9} / \mathrm{L}$, hemoglobin $81 \mathrm{~g} / \mathrm{L}$, platelet count $7.6 \times 10^{9} / \mathrm{L}$, reticulocyte count $0.15 / \mathrm{L}$ ), and hemolytic anemia (total bilirubin $4.6 \mathrm{mg} / \mathrm{dL}$, direct bilirubin $1.3 \mathrm{mg} / \mathrm{dL}$, lactate dehydrogenase $488 \mathrm{U} / \mathrm{L}$; negative result on direct and indirect Coombs tests and hemoglobinuria, cold-agglutinin reaction 256, but direct agglutination test was also negative, and haptoglobin was $8 \mathrm{mg} / \mathrm{dL}$ ), which was diagnosed as $\operatorname{lgM}$ warm autoimmune hemolytic anemia (AlHA), by a positive result on the lgM direct antiglobulin test. Bone marrow (BM) examination revealed myelofibrosis (MF)-1, hyperplastic BM with lymphocytic infiltration, without dysplasia in three lineages (Fig. 1C-f). The patient tested negative for JAK2V617F, CALR, and MPL mutation. Although the initial treatment for AlHA is steroid, as his AlHA type was atypical case, with a difficult diagnosis and delayed treatment, ruxolitinib $20 \mathrm{mg}$ was started daily for MF, which normalized haptoglobin and reticulocyte levels without steroid treatment for AlHA (Fig. 1h). One year after ruxolitinib initiation, repeat BM examination revealed no fibrosis (Fig. 1g); CT showed improvement in splenomegaly (Fig. 1b). Ruxolitinib improved BM fibrosis, splenomegaly, and AlHA.

\section{Conclusions}

Autoimmune myelofibrosis (AIMF) is secondary MF associated with autoimmune diseases [1]. Thus, instead of Primary MF (PMF), the patient was retrospectively diagnosed with AIMF, supported by triplenegative and grade $1 \mathrm{MF}$, and lymphocytic infiltration of the $\mathrm{BM}$, this is consistent with the characteristic 
AIMF findings reported by Vergara-Lluri et al [2]. AIMF does not characteristically cause splenomegaly [1]. Spleen biopsy in this patient showed nonclonal lymphoid infiltrate, without evidence of extramedullary hematopoiesis, indicating AlHA-induced splenomegaly.

The treatment response of secondary MF is similar to that of PMF [3], whereas AIMF responds better than that of other secondary MF. In many cases, single-agent prednisolone can induce blood cell recovery; however, few cases show complete improvement of fibrosis [1].

There are few reports of MF with AlHA as the underlying disease. Fattizo et al. reported that $36 \%$ of AlHA had fibrosis [4]. IL-17 and IFNy levels were correlated with increased LDH levels in AlHA, and predominantly higher transforming-growth factor (TGF)- $\beta$ levels in patients with MF compared to those without fibrosis. They found that, in cases of AlHA-induced AIMF, TGF- $\beta$ produced by lymphocytic BM infiltration induced BM fibrosis. AlHA with AIMF has poor response to PSL monotherapy, with patients requiring secondary therapy more frequently than those with MF0; with $70 \%$ of patients require rituximab, splenectomy, or other immunosuppressive agents, and have worse prognosis than AlHA alone [4]. JAK/STAT3 signaling is required for TGF- $\beta$-mediated transcriptional responses [5]. Ruxolitinib, a JAK/STAT signaling pathway inhibitor targeted drug, inhibits myeloproliferation, proinflammatory cytokine expression, and myeloid remodeling by the JAK-STAT pathway and other downstream pathways [6]. Here, ruxolitinib might improve cytokinemia, especially TGF- $\beta$, indicating effectiveness for both AIMF and AlHA. Rapid improvement of myelofibrosis by ruxolitinib monotherapy in AIMF patients or improvement of the autoimmune disease itself have not been reported previously. Thus, ruxolitinib is a potential therapeutic option for AIMF and AlHA in difficult-to-treat or when steroid therapy is a contraindicated.

\section{Declarations}

\section{Compliance with ethical standards}

Informed consent was obtained from the patient for the treatment.

All procedures performed in studies involving human participants were in accordance with the ethical standards of the institutional and/or national research committee and with the 1964 Helsinki declaration and its later amendments or comparable ethical standards.

i. Funding; Funding information is not available.

ii. Conflicts of interest/Competing interests; The authors declare that they have no conflict of interest.

iii. Ethics approval; The study was conducted in accordance with the Declaration of Helsinki.

iv. Consent to participate (include appropriate statements); Written informed consent was obtained from from patient for publication of this case report and accompanying images.

v. Consent for publication (include appropriate statements); Written informed consent was obtained from from patient for publication of this case report and accompanying images.

vi. Availability of data and material (data transparency); Data sharing not applicable to this article as no datasets were generated or analysed during the current study. 
vii. Code availability (software application or custom code); none.

viii. Authors' contributions; SS was manuscript preparation and provided the pathology description. WK and $\mathrm{YT}$ read and approved the final manuscript.

\section{References}

1. Pullarkat V, Bass RD, Gong JZ, Feinstein DI, Brynes RK. Primary autoimmune myelofibrosis: definition of a distinct clinicopathologic syndrome. Am J Hematol. 2003;72:8-12.

2. Vergara-Lluri ME, Piatek Cl, Pullarkat V, Siddiqi IN, O’Connell C, Feinstein DI, Brynes RK. Autoimmune myelofibrosis: an update on morphologic features in 29 cases and review of the literature. Hum Pathol. 2014;45:2183-91.

3. Breccia $M$, Andriani $A$, Montanaro $M$, Abruzzese $E$, Buccisano $F$, Cedrone $M$, Centra A, Villivà $N$, Celesti F, Trawinska MM, Massaro F, Di Veroli A, Anaclerico B, Colafigli G, Molica M, Spadea A, Petriccione L, Cimino G, Latagliata R. Ruxolitinib in clinical practice for primary and secondary myelofibrosis: an analysis of safety and efficacy of Gruppo Laziale of Ph-negative MPN. Ann Hematol. 2017;96:38791.

4. Fattizzo B, Zaninoni A, Gianelli U, Zanella A, Cortelezzi A, Kulasekararaj AG, Barcellini W. Prognostic impact of bone marrow fibrosis and dyserythropoiesis in autoimmune hemolytic anemia. Am J Hematol. 2018;93:E88-91.

5. Liu RY, Zeng Y, Lei Z, Wang L, Yang H, Liu Z, Zhao J, Zhang HT. JAK/STAT3 signaling is required for TGF- $\beta$-induced epithelial-mesenchymal transition in lung cancer cells. Int J Oncol. 2014;44:1643-51.

6. Verstovsek S, Mesa RA, Gotlib J, Levy RS, Gupta V, DiPersio JF, Catalano JV, Deininger M, Miller C, Silver RT, Talpaz M, Winton EF, Harvey JH, Arcasoy MO, Hexner E, Lyons RM, Paquette R, Raza A, Vaddi K, Erickson-Viitanen S, Koumenis IL, Sun W, Sandor V, Kantarjian HM. A double-blind, placebocontrolled trial of Ruxolitinib for myelofibrosis. N Engl J Med. 2012;366:799-807.

\section{Figures}



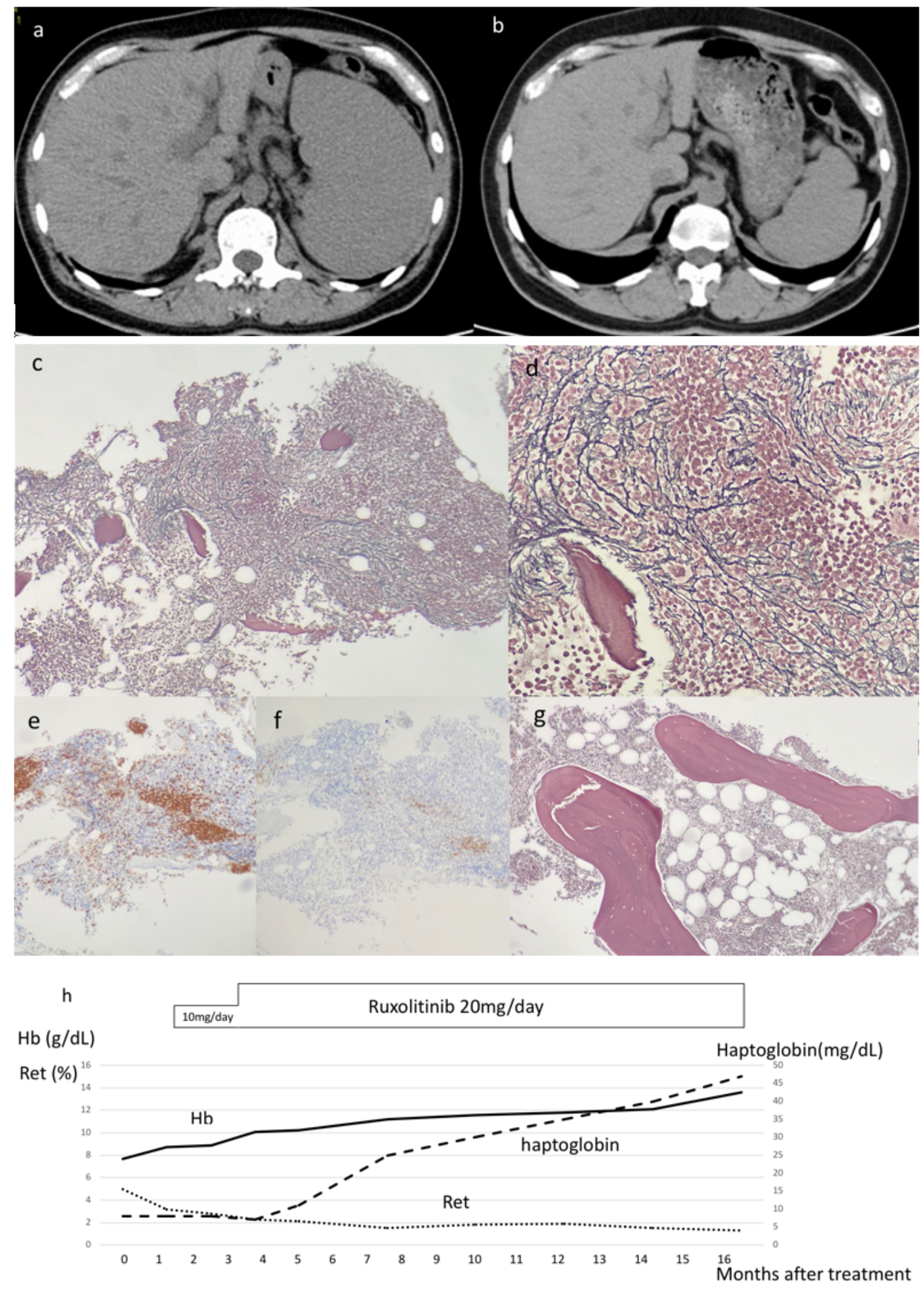

\section{Figure 1}

Before ruxolitinib treatment, abdominal computed tomography (CT) showed splenomegaly (a), and after 15 months of ruxolitinib treatment, splenomegaly has improved (b). Silver-staining of bone marrow biopsy showed MF-1 with a very loose network of reticulin fibers (c; $\times 200, d ; \times 400)$, with focal and interstitial lymphoid infiltrate, mainly of CD3 (+) small T-lymphocytes (e), and very few scattered CD79a $(+)$ small B-lymphoid cells (f). After 15 months of continuous treatment with ruxolitinib, bone marrow 
fibrosis had improved (g). Clinical coarse of the patient (h). We started ruxolitinib at $10 \mathrm{mg}$ daily and he had no problems, we upped to $20 \mathrm{mg}$ daily. Haptoglobin and reticulocyte levels also normalized with only ruxolitinib. 